\title{
Revealing the Molecular Secrets of Marine Diatoms
}

\author{
Angela Falciatore and Chris Bowler \\ Laboratory of Molecular Plant Biology, Stazione Zoologica "A. Dohrn," Villa Comunale, \\ I-80121 Naples, Italy; e-mail: chris@alpha.szn.it
}

Key Words iron, marine algae, photoperception, quorum sensing, silica

- Abstract Diatoms are unicellular photosynthetic eukaryotes that contribute close to one quarter of global primary productivity. In spite of their ecological success in the world's oceans, very little information is available at the molecular level about their biology. Their most well-known characteristic is the ability to generate a highly ornamented silica cell wall, which made them very popular study organisms for microscopists in the last century. Recent advances, such as the development of a range of molecular tools, are now allowing the dissection of diatom biology, e.g., for understanding the molecular and cellular basis of bioinorganic pattern formation of their cell walls and for elucidating key aspects of diatom ecophysiology. Making diatoms accessible to genomics technologies will potentiate greatly these efforts and may lead to the use of diatoms to construct submicrometer-scale silica structures for the nanotechnology industry.

\section{CONTENTS}

DIATOMS AND ECOSYSTEM EARTH $\ldots \ldots \ldots \ldots \ldots \ldots \ldots \ldots \ldots \ldots \ldots \ldots \ldots \ldots \ldots$

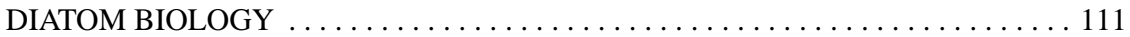

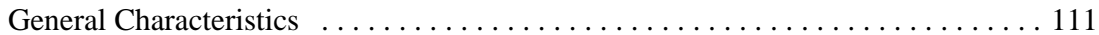

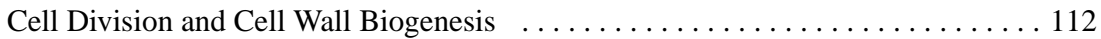

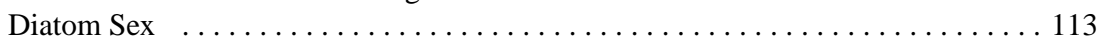

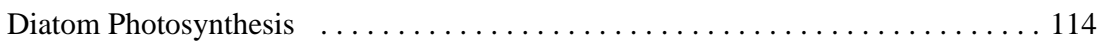

PERCEPTION OF ENVIRONMENTAL SIGNALS $\ldots \ldots \ldots \ldots \ldots \ldots \ldots \ldots \ldots \ldots \ldots \ldots \ldots$

Nutrients . . . . . . . . . . . . . . . . . . . . . . . . . . . 116

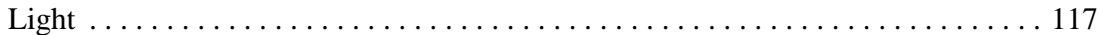

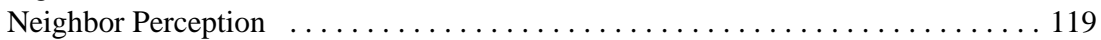

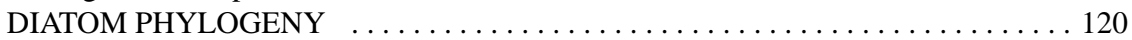

TOWARD A DIATOM MODEL SPECIES $\ldots \ldots \ldots \ldots \ldots \ldots \ldots \ldots \ldots \ldots \ldots \ldots \ldots \ldots$

\section{DIATOMS AND ECOSYSTEM EARTH}

The origin of life and the subsequent changes in oceanic productivity that followed the evolution of photosynthesis have profoundly influenced the geochemistry of the Earth for the past three billion years (29). In the contemporary ocean, marine 
phytoplankton, made up of photosynthetic bacteria such as prochlorophytes and cyanobacteria, and eukaryotic microalgae, such as chromophytes (brown algae), rhodophytes (red algae), and chlorophytes (green algae), represent the major contributors of marine carbon fixation. In some regions of the ocean, these organisms can fix approximately the same amount of carbon, a few grams per square meter per day, as a terrestrial forest (82). Today, the oceans cover 70\% of the Earth's surface, and on a global scale they are thought to contribute approximately one half of the total primary productivity of the planet.

Diatoms are a group of unicellular chromophyte algae that colonize the oceans down to depths to which photosynthetically available radiation can penetrate. They are thought to be the most important group of eukaryotic phytoplankton, responsible for approximately $40 \%$ of marine primary productivity (29). They also play a key role in the biogeochemical cycling of silica (84) owing to their requirement for this mineral for cell wall biogenesis.

There are well over 250 genera of extant diatoms, with perhaps as many as 100,000 species $(71,88)$ ranging across three orders of magnitude in size (about as many as land plants) and exhibiting a remarkable variety of shapes. The wellstudied small-celled species $(5-50 \mu \mathrm{m})$ tend to be most abundant at the beginning of spring and autumn, when nutrients are not limiting and when light intensity and day length are optimal for diatom photosynthesis. When nutrients run out they will often aggregate into flocs that sink quickly out of the photic zone. The giant diatoms (which can reach 2-5 $\mathrm{mm}$ in size) are ubiquitous in all oceans, and their abundance shows less seasonal variability. Their silica cell walls predominate in the sediments of the ocean floor, thus making them serious players in ocean biogeochemistry over geologically significant timescales (45). Besides planktonic diatoms, which are found in all open water masses, there are many benthic forms, growing on sediments or attached to rocks or macroalgae, and some species can also be found in soil (59). Diatoms also constitute a large proportion of the algae associated with sea ice in the Antarctic and Arctic. Furthermore, in warm oligotrophic seas it is possible to find symbioses between nitrogen-fixing bacteria and cyanobacteria and diatoms (91). In these areas the fixation of nitrogen by these endosymbionts contributes a significant amount of nitrogen to the ecosystem.

In spite of their ecological relevance, very little is known about the basic biology of diatoms (78). What are the molecular secrets behind their success? One possibility is that they have an extraordinary capacity for finding different adaptive solutions (e.g., physiological, biochemical, behavioral) to different environments. It has also been proposed that the major factor behind ecological success is their siliceous cell wall (see example in Figure 1). Smetacek $(81,82)$ has argued that the many different shapes and sizes of diatoms evolved to provide a robust first line of defense against various type of grazers, therefore being the functional equivalents of the waxy cuticles, trichomes, and spines of higher plants. Plankton defense systems are poorly studied, but an emerging idea is that protection against grazers may be an important factor in determining the composition and succession 


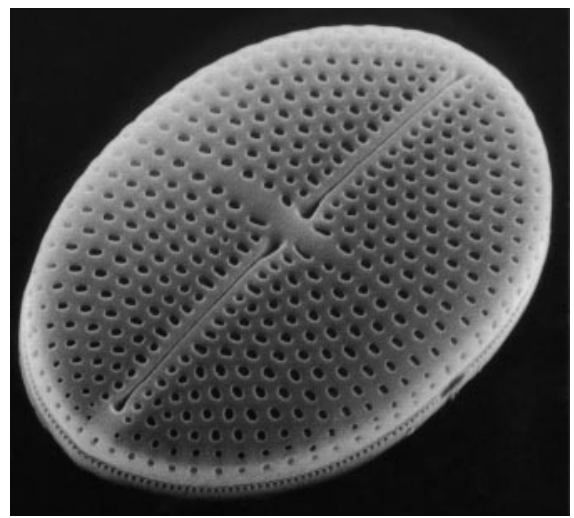

Figure 1 Electron micrograph of the diatom Mastogloia binotata (Grun.) cl. at 5800 times magnification. Photo courtesy of Keigo Osada.

of phytoplankton. If this is the case plankton evolution may be ruled as much by protection as by short-term adaptations or competition (82).

\section{DIATOM BIOLOGY}

\section{General Characteristics}

Diatoms are Bacillariophycea within the division Heterokontophyta (also known as Stramenopiles). Their most characteristic feature is the ability to generate a highly patterned external wall composed of amorphous silica $\left[\left(\mathrm{SiO}_{2}\right) \mathrm{n}\left(\mathrm{H}_{2} \mathrm{O}\right)\right]$, known as the frustule (Figure 1; Figure 2). This is constructed of two almost equal halves, with the smaller fitting into the larger like a Petri dish (Figure 2). The larger of the two halves is denoted the epitheca, and the inner one is denoted the hypotheca. Each theca is typically composed of two parts: the valve (which forms the larger outer surface) and a girdle (circular bands of silica attached to the edge of the valve) (Figure 2). The siliceous material of the frustule is laid down by largely unknown mechanisms in highly regular patterns that leave the wall beautifully ornamented. Pattern design is faithfully reproduced from generation to generation, implicating a strict genetic control of the process. The precision of this nanoscale architecture far exceeds the capabilities of present-day materials science engineering, indicating that the understanding of the process will one day be exploitable in nanotechnological applications (15a, 63, 70, 73).

Diatoms are generally classified into two major groups depending on the symmetry of their frustules (88). Centric diatoms are radially symmetrical, whereas pennate diatoms are elongated and bilaterally symmetrical. The former group tends 
to be planktonic, whereas the latter are benthic, living on sediments or other surfaces. Some of the pennate diatoms are able to glide along surfaces, owing to the presence of a crevice (known as raphe) within one or both of the frustules through which mucilage is secreted to aid movement (Figure 2).

\section{Cell Division and Cell Wall Biogenesis}

As far as is known, vegetative diatom cells are diploid. The normal asexual method of reproduction is by division of one cell into two, with each valve of the parent cell becoming an epitheca of the daughter cell (75). Each daughter cell must therefore generate a new hypotheca (Figure 3). The process of frustule formation is only partially understood and is largely based on microscopical observations. Prior to cell division, the cell elongates, pushing the epitheca away slightly from the hypotheca, and the nucleus divides by an "open" mitosis. After the protoplast has divided in two by invagination of the plasma membrane, each daughter cell must generate a new hypotheca. Remarkably, this structure, which must cover one half of the cell, is commonly generated by the polarized generation of a huge vesicle known as the silica deposition vesicle (SDV). Hypotheca biogenesis involves the laying down of a precise silica lattice work followed by its coating with an organic matrix that prevents its dissolution. Once generated, the entire structure is then exocytosed, after which the two daughter cells can separate. This whole process is not well understood but has been reviewed recently (96).

Analysis of frustule composition has revealed the presence of specific organic components in addition to silica. Modified peptides known as silaffins together with putrescine-derived polyamines bind the silica scaffold extremely tightly and can only be removed following complete solubilization of silica with anhydrous hydrogen fluoride. Both the silaffins and polyamines can promote silica precipitation in vitro, generating a network of nanospheres with diameters between $100 \mathrm{~nm}$ and $1 \mu \mathrm{m}$, depending on the molecules used $(51,52)$. It is therefore possible that such components generate the basic building blocks for silica cell wall formation. Cylindrotheca fusiformis contains two major types of silaffins, denoted silaffin-1A $(4 \mathrm{kDa})$ and silaffin-1B $(8 \mathrm{kDa})$. Both are proteolytically derived from the product of a single gene, denoted Sill.

Hydrogen fluoride-extractable material also contains other proteinaceous fractions of high molecular mass, denoted pleuralins (pleuralin-1 was formerly known as HEP200) (53, 54). Immunolocalization experiments have revealed that pleuralin1 is specifically localized to the terminal girdle band (known as pleural band) of the epitheca but that it is also targeted to the pleural band of the hypotheca of a cell that has mitotically divided but not yet generated a hypotheca (54). It is therefore a terminal differentiation marker for the epitheca. A small gene family encodes pleuralin proteins in the $C$. fusiformis genome, which are localized together (53). All encode proteins with characteristic repeat domains.

Calcium-binding glycoproteins known as frustulins $(49,50)$ have been localized to the outer coating of diatom cell walls (87). To date, five different types 
of frustulins have been described, based on their different molecular weights: $\alpha$-frustulin (75 kDa), $\beta$-frustulin (105 kDa), $\gamma$-frustulin (140 kDa), $\delta$-frustulin $(200 \mathrm{kDa})$, and $\varepsilon$-frustulin $(35 \mathrm{kDa})$, all of which contain characteristic acidic cysteine-rich domains (ACR domains). The function of this domain is not yet known. Immunological studies have demonstrated that, unlike pleuralin-1, the frustulins are localized ubiquitously over the external surface of the cell wall $(53,87)$, although it is possible that individual frustulins have specific localization profiles. Because they are not an integral component of the siliceous cell wall, they are not thought to participate in the silica biomineralization process.

The chemical form of $\mathrm{Si}$ available to marine diatoms is mainly undissociated silicic acid, $\mathrm{Si}(\mathrm{OH})_{4}(65)$. It is transported into diatom cells via novel membranelocalized silica transporters. Five different silicic acid transporter (SIT) genes have been isolated from $C$. fusiformis (40). These genes encode an integral membrane protein with 10 membrane-spanning domains and a long hydrophyllic carboxylterminal region containing coiled-coil domains, possibly involved in mediating interactions with other proteins. Heterologous hybridization experiments have revealed that such genes are likely to be present in other diatom species. This new class of transporter, which has no known homologs beyond the diatoms, has been functionally characterized as a silicic acid transporter by overexpressing the cDNA in Xenopus laevis oocytes (40,40a). Analysis of SIT gene regulation indicated that they are differentially expressed during cell division and cell wall biogenesis (65). To explain these variations it has been hypothesized that different SIT proteins could have distinct transport characteristics or subcellular localizations.

The deposition of new siliceous valves between mitosis and daughter cell separation necessitates a precise coupling between silicon metabolism and the cell cycle (65). In several species, it has been observed that silica uptake precedes cell division (88). A series of silica-dependent steps have been identified during diatom cell division. Two arrest points appear universal, one at the G1/S boundary and another during G2/M associated with the construction of new valves (16). The arrest point at G1/S has been hypothesized to be indicative of a silica dependency for DNA synthesis, and the data of Vaulot and coworkers $(89,89 a)$ suggest that this block serves to determine whether sufficient silica is available to allow completion of frustule biogenesis.

\section{Diatom Sex}

For the vast majority of diatom species, the Petri-dish nature of the frustule and its unusual mode of biogenesis lead to a reduction in size during successive mitotic divisions in one of the daughter cells (Figure 3). Mitotically dividing diatom populations therefore decrease in size over time. Regeneration of the original size typically occurs via sexual reproduction, followed by auxospore formation. Gametogenesis occurs once cells decrease in size to approximately $30-40 \%$ of the maximum diameter. This is known as the critical size threshold. The resulting male and female gametes combine to create a diploid auxopore that is larger than 
either parent. This newly created cell then proceeds along the asexual pathway until an appropriate trigger once again elicits gametogenesis. Sexual reproduction in diatoms involves a range of mechanisms (reviewed in 62). In centric diatoms, sex is almost universally oogamous, with flagellated male gametes. Within the pennate diatoms, there is much more variety, including anisogamy, isogamy, and automixis. Only fragmentary information is available because almost all studies are based on microscopic observation of what is a very rare event. Diatom sexuality is in fact limited to brief periods (minutes or hours) that may occur less than once a year in some species and that involve only a small number of vegetative cells within a population (62).

Sex can sometimes be induced when vegetative cells are exposed to unfavorable growth conditions. Factors such as light, nutrients, salinity, and temperature shifts $(5,89,89 \mathrm{a})$ have all been reported to induce the switch from asexual to sexual reproduction in some diatoms. Armbrust has identified a new gene family expressed during the onset of sexual reproduction in the centric diatom Thalassiosira weissflogii, by exploiting the fact that sexuality within this species can be induced by a shift in the diurnal light regime (3). Three of the sexually induced genes, Sigl, Sig2, and Sig3, are members of a novel gene family that encode proteins containing epidermal growth factor (EGF)-like domains present in extracellular proteins that promote cell-cell interactions during different stages of development in animals. The strong sequence similarity to components of the extracellular matrix (ECM) of mammalian cells is interesting in that the ECM is not present in higher plants. It has been suggested that the SIG polypeptides are involved in sperm-egg recognition (3).

\section{Diatom Photosynthesis}

Like in other photosynthetic eukaryotes, the photosynthetic apparatus of diatoms is housed within plastids inside the cell. The thylakoid membranes within the plastid have the typical structure of the Heterokontophyta, grouped into stacks (lamellae) of three, all enclosed by a girdle lamella (Figure 2) (88). Diatoms are brown in color owing to the presence of the accessory carotenoid pigment fucoxanthin, which is located together with chlorophyll $a$ and $c$ in their plastids. For this reason, diatom and other brown algal plastids have been called phaeoplasts, to distinguish them from the rhodoplasts and chloroplasts of red and green algae, respectively. Centric diatoms generally have large numbers of small discoid plastids, whereas pennate diatoms tend to have fewer plastids, sometimes only one (88). Fucoxanthin and chlorophylls are bound within the light-harvesting antenna complexes by fucoxanthin, chlorophyll a/c-binding proteins (FCP).

The FCP proteins are integral membrane proteins localized on the thylakoid membranes within the plastid, and their primary function is to target light energy to chlorophyll $a$ within the photosynthetic reaction centers (72). In the pennate diatom Phaeodactylum tricornutum, two FCP gene clusters have been identified containing, respectively, four and two individual $F C P$ genes (12). They show sequence 
similarity to the chlorophyll $a / b$-binding protein genes $(C A B)$ of plants and green algae. Like $\mathrm{CAB}$ proteins, diatom FCP proteins are encoded in the nucleus. Although they are functionally and structurally strongly related to higher plant $\mathrm{CAB}$ proteins, the transport mechanisms that target them to the diatom plastid are very different, owing to the fact that diatom plastids are enclosed within four membranes rather than two membranes as in land plants (see Diatom Phylogeny below). The $\mathrm{N}$-terminal translocation sequences of immature FCP proteins are in fact bipartite. One of these is likely to be utilized for translocation through the outer membrane, whereas the other (a more conventional plastid transit peptide) is utilized for transport through the inner two membranes (11). The former sequence resembles an endoplasmic reticulum signal peptide and, indeed, is capable of cotranslational import and processing by microsomal membranes. The process of plastid protein targeting and import has been more thoroughly studied for a related presequence from the $\gamma$ subunit of the plastid ATP synthase from the centric diatom Odontella sinensis (55).

In $T$. weissflogii, semiquantitative RT-PCR analysis of $F C P$ gene expression revealed that transcript levels decrease during prolonged darkness and are highly induced following a subsequent shift to white light (58). In Dunaliella tertiolecta, a marine green alga, a shift from high to low irradiance leads to a rapid induction of $C A B$ gene expression (57). It has been proposed that this regulation allows increased production of light-harvesting pigment complexes in conditions of low light intensity and that redox signaling from the chloroplast to the nucleus controls the process (25). It will be interesting to determine whether such mechanisms also exist in diatoms and whether they contribute to the ability of diatoms to photosynthesize at optimal levels over a wide range of light intensities (30).

One potentially significant observation that has recently been made is that diatoms may be capable of $\mathrm{C}_{4}$ photosynthesis (77). This is a specialized form of photosynthesis that is restricted to a few land plants, such as sugar cane and maize, and that allows a more efficient utilization of available $\mathrm{CO}_{2}$. The report by Reinfelder and colleagues is the first description of $\mathrm{C}_{4}$ photosynthesis in a marine microalga, and the data suggest that $\mathrm{C}_{4}$ carbon metabolism may be confined to the cytoplasm, away from the RUBISCO-dependent reactions within the plastid. If shown to be a universal feature of diatoms, $\mathrm{C}_{4}$ photosynthesis may provide a further explanation for their ecological success in the world's oceans, in that it provides a means of storing carbon for use in less favorable conditions. Identification of the genes encoding key enzymes of $\mathrm{C}_{4}$ metabolism will provide the molecular tools for exploring the universality of this type of photosynthesis in diatoms.

\section{PERCEPTION OF ENVIRONMENTAL SIGNALS}

Living organisms are constantly bombarded with information to which they must react. In plant cells, both external and internal signals are amplified and communicated by complex signal transduction pathways, most of which are initiated by the activation of receptor proteins (85). The marine environment potentially contains 
a great number of physicochemical signals that can be utilized to control organismal adaptive responses to changing local conditions. The importance of molecular sensing of environmental signals in diatoms has recently been examined by studying calcium-dependent signal transduction in P. tricornutum (28). Transgenic diatom cells containing the calcium-sensitive photoprotein aequorin were generated to follow changes in calcium homeostasis in response to a range of relevant environmental stimuli. The results revealed sensing systems for detecting and responding to fluid motion, osmotic stress, and nutrient limitation. In particular, an exquisitely sensitive calcium-dependent signaling mechanism was induced by iron, a key nutrient controlling diatom abundance in the ocean (see below). Based on our knowledge of calcium signaling in other organisms, the physiological responses of diatoms to environmental changes are therefore likely to be regulated by sense-process-respond chains involving specific receptors and feedback mechanisms, whose activity is determined by the previous history of the cell. The further characterization of signal transduction pathways that tune cellular metabolism to ambient light and nutrient levels will be an important step for understanding the molecular mechanisms that contribute to the ecological success of diatoms.

\section{Nutrients}

External nutrient concentrations are key regulators of phytoplankton growth. In the marine environment, nutrients such as nitrate, silicate, and phosphate are extremely important, and strong evidence also implicates dissolved iron as being a limiting resource for phytoplankton growth in many regions of the oceans (see 29 and references therein). The "iron hypothesis" has been tested and supported through in situ iron fertilization experiments in the equatorial Pacific Ocean and elsewhere $(15,18,64)$, which resulted in a clear and unambiguous physiological response to the addition of iron-a massive phytoplankton bloom of predominantly diatoms. Subsequently, some effort has been dedicated to developing methods to determine iron deficiency in phytoplankton in situ. Flavodoxin is the first such example of a molecular marker for studying diatom cell physiology in their natural context (56). Because the appearance of this protein correlates with iron deficiency, flavodoxin has been used as an immunological probe to map the degree of iron stress in natural populations.

To better understand some of the nutrient-sensing mechanisms in marine algae, it will be necessary to clone genes encoding nutrient transporters. Besides the previously described silicic acid transporters (SIT), Hildebrand \& Dahlin recently reported the cloning and initial characterization of the first genes encoding nitrate transporters (NAT) in a marine organism, from the diatom C. fusiformis (39). The NAT proteins are predicted to have 12 membrane-spanning domains with hydrophyllic amino- and carboxy-termini that are located in the cytoplasm. The proteins show significant homology to the nitrate transporter family NRT2 of Aspergillus nidulans, but no similarity to the NTR1 class of Arabidopsis. NAT gene expression in $C$. fusiformis was sensitive to both the level and the type of 
nitrogen source added: Transcript levels were high in the presence of nitrate, were lower in nitrite-grown cultures, and were highly repressed when ammonium was used as the nitrogen source. Southern hybridization experiments indicated that at least four copies of NAT genes are present in C. fusiformis and that multiple copies are present in other diatom species, thus raising the exciting possibility of developing "universal" probes for estimating nitrate transport capacity in marine samples.

Interestingly, we have recently found expressed sequence tags (ESTs) of $P$. tricornutum encoding proteins with high homology to several other channel and transporter proteins (e.g., copper transporter, ammonium transporter, $\mathrm{ABC}$ transporter, glycine betaine transporter, inorganic phyrophosphate transporter) (79). The generation of ESTs therefore provides a powerful new approach for elucidating nutrient transport systems in diatoms.

Owing to the important role played by iron in controlling phytoplankton growth, it will be important to clone iron transporter genes. Recently a gene encoding a membrane protein directly involved in $\mathrm{Fe}$ (III) uptake was cloned from maize (19) by complementation of a yeast iron uptake mutant. Expression of the maize gene in the mutant restored growth on Fe(III)-phytosiderophore media. Similar complementation experiments in yeast could be useful for identifying such proteins in diatoms.

\section{Light}

Light is another essential factor regulating the abundance of photosynthetic organisms in the oceans. In addition to constituting their principal energy source, it provides microalgae with positional information from their local environment. As previously mentioned, it is known that marine phytoplanktonic organisms are extremely efficient at photoacclimation and that they are highly sensitive to changes in spectral quality and light intensity (30). Although much is known about the mechanisms of photoperception and signal transduction in plants living on land, the marine environment imposes different constraints. The spectral distribution of solar irradiance is identical only on land and at the surface of water. Light fluence and quality change drastically with depth, and in oceanic waters, blue light predominates at greater depths (46). Furthermore, land plants are immobile, whereas many algae live suspended along the water column and can experience dramatic changes in the light field. Consequently, phytoplanktonic organisms are likely to have developed different ecological strategies to adapt to the variability of the light conditions. For example, complementary chromatic adaptation is a process by which cyanobacteria alter the composition of their photosynthetic lightharvesting apparatus (the phycobilisomes) in response to the spectral quality of the available light (36). Kehoe \& Grossman reported that the chromatic adaptation sensor is similar to plant phytochrome photoreceptors (44).

Recently, Béjà et al. $(7,8)$ described a new type of bacterial rhodopsin, discovered through genomic analyses of naturally occuring marine bacterioplankton, 
that can mediate light-driven proton-pumping activity. These data indicate that an unsuspected phototrophic pathway of bacterially mediated light-driven energy generation may occur in the oceans and influence significantly the fluxes of carbon and energy.

Another method that phytoplankton utilize to respond to light fluctuations is movement. Many photosynthetic flagellate algae actively search for optimal light conditions by means of phototaxis (80). The green alga Chlamydomonas reinhardtii has developed a rudimentary light-sensing system that enables it to measure the light intensity and direction in an eyespot, a highly pigmented organelle in an almost equatorial position of the cell. The photoexcitation of a rhodopsin-type photoreceptor in the eyespot generates a photoreceptor current across the eyespot region of the cell membrane that can induce flagellar movement.

Planktonic diatoms are not able to move actively because they do not have flagella, thus they are subject to passive movements such as sinking and water turbulence. The diatom Ditylum brightwellii can move up and down the water column by changing the ionic composition of its large vacuole (32). Other species can control their buoyancy by making colonies, which slows settling in the water column because of the increase in surface to volume ratio (59). Some benthic diatoms, on the other hand, move by a mechanism involving the secretion of mucilage through their raphe slit (59). Indeed, some diatoms living in sediments have been observed to migrate up to the surface before dawn and down again during the first hours of darkness or to move up and down according to the tides (38). In some locations, this phenomenon is so dramatic that the sand can be observed to change color. Some, albeit limited, action spectra have been performed to study diatom phototaxis (38).

Light-mediated plastid reorientation has been reported in different diatom species. The action spectrum for plastid orientation in Pleurosira laevis revealed that two different photoreceptors could be involved in this response: a green lightsensitive photoreceptor that controls plastid dispersion and a UV-A/blue lightsensitive system that controls plastid assemblage (33). It is logical to propose that a phototropin-type photoreceptor, homologous to Arabidopsis NPL1, is responsible for the latter phenomenon (43).

To further understand photoperception mechanisms in diatoms, Leblanc et al. (58) performed action spectra of $F C P$ gene expression using the Okazaki large spectrograph. These experiments revealed responses to UV-A, blue, green, red, and far-red light wavelengths, suggesting the presence of cryptochrome-, rhodopsin-, and phytochrome-like receptors in marine diatoms. The apparent presence of phytochrome-mediated responses is of particular interest given the low fluences of red and far-red light wavelengths in marine environments. In fact, because water selectively absorbs light of longer wavelengths, most of the light below $15 \mathrm{~m}$ is confined to the blue-green (400-550 nm) region of the spectrum (46). However, recent estimates of irradiance at red wavelengths, produced by the natural fluorescence of chlorophyll in marine phytoplankton, support the idea that these signals could also be perceived and utilized as information even below the depth of maximal penetration of solar-derived red light (M. Ragni \& M. Ribera, manuscript in 
preparation). Clearly then, isolation of phytochrome photoreceptors and the subsequent elucidation of their function in diatoms, whose phylogeny is separated from that of higher green plants and from other algae (see below) (79), will provide exciting information about the photoperception mechanisms utilized in the aquatic environment and promises to reveal new insights into photoreceptor evolution.

\section{Neighbor Perception}

In addition to the physico-chemical signals described above, marine organisms are also likely to be able to sense and respond to the presence of other organisms, both friend and foe. Interestingly, marine diatoms are able to control the population size of the zooplankton that eat them. Miralto et al. (69) reported that diatoms synthesize specific aldehyde molecules that can arrest mitosis during egg development of their principal grazers, the copepods. These molecules also display antimitotic activity in diatoms (17). In addition to being defined as "defense molecules," these aldehydes may therefore have a "signaling" role for controlling diatom population size, e.g., by acting as a suicide trigger for bloom termination. Such a proposal is a radical alternative to the traditional dogmas about bloom decline based on nutrient depletion.

A related phenomenon that has been well studied in bacteria is quorum sensing (74). Quorum sensing is a cell-density-dependent regulation of specific gene expression in response to extracellular chemical signals, produced by the bacteria themselves. The most well-studied signaling system is the acyl-homoserine lactone (Acyl-HSL) system, used by a large number of Gram-negative bacteria that interact with plant and animal hosts. When the population reaches a critical density within a host, the Acyl-HLS signal, produced by specific enzymes and detected by specific receptors, activates the expression of specific genes necessary for continued success in the host (74). Signals such as these enable individual bacteria to function in a more multicellular manner by coupling gene expression to the attainment of an optimal population size.

One example of intercellular communication in diatoms can be inferred from studies of iron uptake mechanisms in algal communities (41). In this work, it was demonstrated that different algae utilize different complexed forms of iron, e.g., cyanobacteria can transport Fe-complexed siderophores, whereas diatoms preferentially utilize iron complexed in porphyrins. Because siderophores are important molecules in cyanobacterial metabolism, as are porphyrins in diatom metabolism, such specifically differentiated uptake mechanisms provide a means whereby algal cells of the same type can "altruistically" preserve the well being of their own community, but not of others. This could also be used for quorum sensing.

Similarly, the natural fluorescence of chlorophyll in marine phytoplankton could be utilized by individual cells to detect the presence of neighboring organisms (M. Ragni \& M. Ribera, manuscript in preparation). Confirmation of the existence of such a fluorescence-based system of neighbor perception would be of great interest and would have far-reaching implications for phytochrome photoreceptor evolution. 


\section{DIATOM PHYLOGENY}

The plastids of all photosynthetic organisms are likely to have arisen at least 1.5 billion years ago from the engulfment of a photosynthetic bacterium by a unicellular eukaryotic heterotroph $(86,88)$. Analysis of the sequences of plastid genomes from a range of eukaryotic algae and from higher and lower plants clearly supports the hypothesis that all photosynthetic eukaryotes are derived from a single endosymbiotic event involving a photosynthetic bacterium highly similar to extant cyanobacteria $(9,21,48,76)$. Functional analysis of the photosynthetic apparatus from different algae also supports this view (e.g., 92). Hence, all plastids appear to have a monophyletic origin.

Current knowledge suggests that the initial endosymbiotic event gave rise eventually to two major plastid lineages: chloroplasts and rhodoplasts. Green algae, as well as their descendants, the higher plants, contain chloroplasts that are characterized by the presence of stacked thylakoid membranes and the use of chlorophyll $a$ and $b$ for light harvesting. Red algae, on the other hand, contain rhodoplasts, which utilize chlorophyll $a$ and phycobilisomes for the capture of light energy.

Chromophyte algae, such as diatoms, differ fundamentally from the majority of photosynthetic eukaryotes: Whereas the plastids of red algae, green algae, and plants are normally surrounded by two membranes, diatom plastids have four membranes. It is therefore believed that diatoms and related chromophyte algae arose following a secondary endosymbiotic event in which a eukaryotic alga was engulfed by a second eukaryotic heterotroph $(21,34)$. In such a scenario, a flagellate host contributed the nucleus, endomembranes, and mitochondria to the chimera, whereas the photosynthetic endosymbiont provided its plastid and plasma membrane (that perhaps became the inner three membranes of the plastid). Such a hypothesis is supported by the finding of a second nucleus (the nucleomorph) between the outer and inner two membranes in some chromophytes, presumably derived from the nucleus of the ancestral algal endosymbiont (21). The nucleomorph of the chromophyte Guillardia theca was recently sequenced (22). The genome is highly reduced $(0.55 \mathrm{Mb})$ and lacks almost all genes for metabolic functions, which have been transferred to the nucleus of the secondary host. There are, however, 30 genes for plastid-localized proteins, and all these genes are essential for plastid function, presumably explaining why the nucleomorph has persisted during evolution.

Analysis of plastid ribosomal RNAs as well as comparisons of plastid genomes strongly support the hypothesis that diatom plastids were derived from a secondary endosymbiosis involving an alga from the rhodoplast lineage $(10,21,48)$. However, diatoms have not retained phycobilins for light harvesting and instead use chlorophyll $a$ and $c$ together with the brown carotenoid fucoxanthin (chlorophyll $b$ is never found in diatoms).

The ancestral heterotrophic host that paired with the red alga to give rise to the phaeoplast lineage is believed to have been a small unicellular flagellate belonging to the Oomycetes (lower fungi) and similar to Cafeteria roenbergensis $(66,88)$. 
Guillou et al. (37) have subsequently identified a new class of biflagellate algae, the Bolidophyceae, that appears to be a sister group of the diatoms. Phylogenetic analysis based on SSU rDNA sequences together with the discovery of fucoxanthin as a major carotenoid strongly suggest that these newly identified Bolidomonas species could be similar to the ancestral heterokonts that gave rise to the diatom lineage (66). This hypothesis is also consistent with the most recent eukaryotic phylogenetic trees (6).

The fossil record suggests that the secondary endosymbiotic event is unlikely to have occurred much before the Permian-Triassic boundary, between 259 and 285 million years ago, just prior to the end-Permian mass extinction $(66,67)$. It has been proposed that the combination of autotrophy with the ability to form resting spores in the heterokont algae may have allowed them to survive the mass extinction and to subsequently diversify into the many heterokont classes that are currently in existence (67). The oldest diatom fossils clearly represent centric species, whereas pennate diatoms appear to have evolved much later (88).

In phylogenetic terms, diatoms therefore appear to have long since lost contact with the green algal lineage from which higher plants are derived and have followed a parallel evolutionary path for at least 650 million years (9). Analysis of several thousand ESTs generated by random sequencing of P. tricornutum cDNAs indeed confirms that many diatom genes are more homologous to animal rather than plant counterparts (79).

\section{TOWARD A DIATOM MODEL SPECIES}

The arrival of the new millenium has brought a paradigm shift in biological research. No longer are we confined to the study of single genes and single isolated phenomena, as was the case for the past 30 years or so. The completion of several genome projects and the sheer volume of sequence data available in the public databases now allow the simultaneous study of several thousand genes as well as the possibility of finely dissecting highly complex processes at the whole-genome level.

In the year 2002, where does diatom research stand? Perhaps up until now, the most significant success stories have been a realization of the importance of diatoms for aquatic and marine ecosystems and a convincing theory of their phylogenetic origins $(10,21,48,66,88)$. But their unique origins and ecological success imply that they possess many novel cellular characteristics.

Unfortunately, many of the molecular secrets of diatoms still await discovery, mainly as a result of a complete lack of the necessary methodologies. However, in the last few years, a serious effort has been made to establish the molecular-based techniques required to understand the basic biology of these organisms (78). The recent development of genetic transformation systems for a limited number of diatoms has removed one of the major bottlenecks for such studies $(1,24,26,31)$. These systems are based on helium-accelerated particle bombardment of exogenous DNA, followed by selection of transfected cells using antibiotics. An 
important factor behind the success of these experiments was the realization that endogenous promoter and regulatory sequences are necessary to drive the expression of foreign genes.

Genetic transformation technologies are most advanced for the pennate diatom $P$. tricornutum in which a range of antibiotic resistance genes can be used to select for transgenic clones, including phleomycin, kanamycin, and nourseothricin $(1,26,94)$. Even though transformation efficiencies are low, on the order of $10^{-6}$ per $\mu \mathrm{g}$ plasmid DNA, it is possible to co-transform plasmids without selectable markers at an efficiency of approximately $60 \%$. Reporter genes commonly used in other systems such as chloramphenicol acetyl transferase, luciferase, $\beta$-glucuronidase, and green fluorescent protein (GFP) (27) can now be easily introduced and expressed in P. tricornutum. These reporter genes can provide the molecular tools for many experimental applications, such as identifying sequences important for controlling the transcription of genes and for defining the subcellular localization of specific proteins.

Genetic transformation is also an essential tool for enhancing the applied aspects of diatom research. Dunahay et al. $(23,24)$ attempted to enhance lipid biosynthesis in Cyclotella cryptica by introducing multiple copies of the acetyl CoA carboxylase gene. Most significantly, Zaslavskaia et al. (95) recently reported the trophic conversion of $P$. tricornutum, an obligate photoautotroph, into a heterotroph by metabolic engineering. In this work, genes encoding glucose transporters from human erythrocytes (glutl) or from the microalga Chlorella kessleri (hupl) were expressed in P. tricornutum, and the transgenic cells exhibited glucose uptake and were able to grow in the absence of light. The trophic conversion of $P$. tricornutum and other diatoms may increase the use of fermentation technology for large-scale commercial exploitation of diatoms by overcoming the financial and logistical limitations associated with light-dependent growth. Moreover, this conversion will facilitate the generation of photosynthetic mutants, which will help researchers to understand diatom photosynthesis, as has proved so successful in the green alga $C$. reinhardtii $(35,38 \mathrm{a})$.

What should be the major future objectives in diatom research? First and foremost, research should concentrate on the novel aspects of diatom biology. In our opinion the most important research objectives can be classified into three groups:

1. ecological: elucidation of the molecular mechanisms underlying the ecological success of diatoms;

2. cell biological: elucidation of novel protein targeting mechanisms; diatom life cycles, including the regulation of critical size thresholds and diatom sex; silica-based bioinorganic pattern formation and its genetic basis;

3. nanotechnological: harnessing the novel mechanisms responsible for the fabrication of micrometer-scale silica structures for new industrial applications.

For all of these aspects it is essential that multiparallel molecular genetic approaches be developed to underpin research efforts. First and foremost, more information about the characteristics of diatom genomes is required: e.g., What is the 
range in genome size from species to species? What is the corresponding range in chromosome number? Can diatom sex be controlled to allow genetic crosses to be performed under defined laboratory conditions? Are there significant differences in GC content, codon usage, and methylation?

Although there are some answers to these questions in the literature (e.g., $20,42,47,79,90)$, the available information is fragmentary and incomplete. A clear priority is simply to catalog more diatom genes, e.g., through EST programs, as has recently been reported in P. tricornutum (79). In this regard, it is incredible that up until last year the public databases of DNA sequences contained less than 50 accessions for nuclear-encoded protein coding sequences from diatoms. EST programs in other diatom species should be initiated to allow interspecies differences to be determined.

With increasing interest in understanding the ecological importance of diatoms, it has become clear that more molecular tools must be developed. Moreover, almost all studies have been performed on pennate diatom species such as $P$. tricornutum and $C$. fusiformis, neither of which possesses highly ornamented cell walls nor has significant ecological importance. However, it is difficult to identify a diatom species that is of universal ecological importance. Perhaps the closest is Skeletonema costatum, which is more or less ubiquitous in all coastal waters $(59,88)$. Genetic transformation has not yet been reported in this species.

In addition to extending technologies to ecologically relevant diatom species, it is important to improve existing transformation efficiencies. If several hundreds or thousands of independent transformants could be obtained from a single transformation experiment, it would be possible to generate whole libraries containing different insertions. This could be useful to generate insertionally mutagenized libraries in which every single diatom gene had been randomly inactivated. It would also permit the rational utilization of reverse genetics approaches to identify novel promoters or protein targeting sequences, e.g., by using promoterless or ATG-less GFP constructs. Establishing other technologies, e.g., for inactivating gene expression, is also important. Because the limited information available suggests that homologous recombination is unlikely in diatoms (26), alternative systems must be developed to allow the specific inactivation of specific genes, such as antisense and sense suppression, and RNA interference (83,93). Owing to the universality of the basic cellular mechanisms exploited in these approaches, there is a good likelihood that they will be effective in diatoms.

It is reasonable to expect that within the next five years a diatom genome will be sequenced. Before this happens, the diatom research community will have to decide which species to use. The situation is in some ways analogous to that of the early 1990s when the plant research community decided to focus efforts on Arabidopsis thaliana. At the time, there was considerable controversy over the decision-tobacco had been used much more extensively in molecular research because of the ease with which it could be transformed, and the agricultural lobby was much more in favor of sequencing the genome of a plant of agricultural interest. Nonetheless, the choice to use Arabidopsis prevailed and now, with the 
availability of its complete genome sequence (2) as well as powerful functional genomics platforms in several research centers worldwide, it is clear that the right decision was made.

Which diatom species should be chosen for genome-level research? Essential requirements include:

1) ease of growth under defined laboratory conditions,

2) ease of genetic transformation,

3) small genome size,

4) availability of genetic-based methodologies (isolation of mutants, a genome map, sexual crosses),

5) knowledge of basic biochemistry.

Currently, no single diatom species can fulfill these criteria and represent, at the same time, a good model from an ecological point of view. Those that come closest are P. tricornutum and C. fusiformis, at least for criteria 1, 2, and 5. Both have also been reasonably well studied in terms of ecology and physiology. However, sex has not been described in either of them. The genome size of $P$. tricornutum was measured as between 55 and $100 \mathrm{Mb}(20,90)$, the smallest of any diatom examined in previous work (90). Subsequent measurements by us (79) and by M. Hildebrand (personal communication) have found the P. tricornutum genome to be more on the order of $15 \mathrm{Mb}$, slightly higher than that of the yeast Saccharomyces cerevisiae, whose sequence was completed in 1997 (68), whereas the C. fusiformis genome is approximately $60 \mathrm{Mb}$. It is important to note that several thousand ESTs have been generated from $P$. tricornutum, and its genome properties have been characterized in much more detail than any other diatom (79). Its genome displays very low levels of methylation, normally associated with transcriptionally inactive DNA, suggesting that its genome is gene dense with only low amounts of noncoding "junk" DNA (42). It would therefore appear to be the best choice for a sequencing initiative. Furthermore, recent research in our laboratory using transgenic marker genes suggests that it is possible to perform sexual crosses with this species (O. Malakhova \& C. Bowler, unpublished observations).

However, P. tricornutum is a rather atypical diatom in that it is polymorphic. It exists as three different morphotypes (oval, fusiform, and triradiate), which are only partially silicified (Figure 4) $(13,14,60,61)$. Nonetheless, phylogenetic analysis performed on $18 \mathrm{~S}$ rRNA places it in the middle of the pennate diatom lineage (D. Vaulot, personal communication). It would therefore appear that P. tricornutum is the most appropriate diatom for a genome sequencing project, at least for pennate diatoms.

A parallel project could also be considered for a centric diatom, although in this case it is very difficult to choose a representative model. Even less molecular work has been conducted with centric diatoms, in spite of their enormous ecological relevance. One of the more commonly studied is T. weissflogii, which could be transiently transfected with a GUS reporter gene (26). Furthermore, competitive 
semiquantitative RT-PCR techniques have been optimized for gene expression studies with this organism (58). At this time, the only centric diatom that can be stably transformed is $C$. cryptica (24). Armbrust recently characterized the structural features of the eight known nuclear genes of $T$. weissflogii, with the goal of furthering the potential of this diatom for molecular studies (4). However, the development of molecular tools for this diatom is just beginning, and the time might be premature to determine if it could be the best centric diatom for a genome sequence project. As an alternative, some researchers have proposed Thalassiosira pseudonana, which appears to have a genome size similar to that of P. tricornutum (M. Hildebrand, personal comunication). At press time, this diatom was on the list of organisms to be sequenced by the U.S. Department of Energy (http//www.er.doc.gov/production/ober/EPR/mig_cont.html).

In conclusion, although diatom research has made some important advances in recent years, it is clear that radical measures are required to make it accessible to the enormously powerful genomic and postgenomic research platforms. Given the novelty and potential applicability of certain aspects of diatom ecology and cell biology, this is surprising. However, now that a range of molecular technologies are in place, we hope that more researchers will be attracted to this field so that progress can be accelerated.

\section{ACKNOWLEDGMENTS}

We thank all the numerous colleagues who have helped us to understand diatom biology over the past years. We are especially grateful to Mark Hildebrand and Daniel Vaulot for sharing unpublished information and to Ian Nettleton for the illustrations. We apologize that, owing to size restrictions, it has not been possible to discuss all the work of our colleagues. Finally, this review is dedicated to the memory of Gaetano Salvatore, without whom our research on diatoms would never have begun.

\section{Visit the Annual Reviews home page at www.annualreviews.org}

\section{LITERATURE CITED}

1. Apt KE, Kroth-Pancic PG, Grossman AR. 1997. Stable nuclear transformation of the diatom Phaeodactylum tricornutum. Mol. Gen. Genet. 252:572-79

2. Arabidopsis Genome Initiative. 2000. Analysis of the genome sequence of the flowering plant Arabidopsis thaliana. $\mathrm{Na}$ ture 408:796-815

3. Armbrust EV. 1999. Identification of a new gene family expressed during the onset of sexual reproduction in the centric di- atom Thalassiosira weissflogii. Appl. Env. Microbiol. 65:3121-28

4. Armbrust EV. 2000. Structural features of nuclear genes in the centric diatom Thalassiosira weissflogii (Bacillariophyceae). J. Phycol. 36:942-46

5. Armbrust EV, Chisholm SW. 1990. Role of light and the cell cycle on the induction of spermatogenesis in a centric diatom. $J$. Phycol. 26:470-78

6. Baldauf SL, Roger AJ, Wenk-Siefert I, 
Doolittle WF. 2000. A kingdom-level phylogeny of eukaryotes based on combined protein data. Science 290:972-77

7. Béjà $\mathrm{O}$, Aravind $\mathrm{L}$, Koonin EV, Suzuki MT, Hadd A, et al. 2000. Bacterial rhodopsin: evidence for a new type of phototrophy in the sea. Science 289:1902-6

8. Béjà $\mathrm{O}$, Spudich EN, Spudich JL, Leclerc M, DeLong EF. 2001. Proteorhodopsin phototrophy in the ocean. Nature 411: 786-89

9. Besendahl A, Qiu YL, Lee J, Palmer JD, Bhattacharya D. 2000. The cyanobacterial origin and vertical transmission of the plastid tRNA(Leu) group-I intron. Curr. Genet. 37:12-23

10. Bhattacharya D, Medlin L. 1995. The phylogeny of plastids: a review based on comparisons of small-subunit ribosomal RNA coding regions. J. Phycol. 31:48998

11. Bhaya D, Grossman A. 1991. Targeting proteins to diatom plastids involves transport through an endoplasmic reticulum. Mol. Gen. Genet. 229:400-4

12. Bhaya D, Grossman AR. 1993. Characterization of gene clusters encoding the fucoxanthin chlorophyll proteins of the diatom Phaeodactylum tricornutum. Nucl. Acids Res. 21:4458-66

13. Borowitzka MA, Chiappino ML, Volcani BE. 1977. Ultrastructure of a chainforming diatom Phaeodactylum tricornutum. J. Phycol. 13:162-70

14. Borowitzka MA, Volcani BE. 1978. The polymorphic diatom Phaeodactylum tricornutum: ultrastructure of its morphotypes. J. Phycol. 14:10-21

15. Boyd PW, Watson AJ, Law CS, Abraham ER, Trull T. 2000. A mesoscale phytoplankton bloom in the polar Southern Ocean stimulated by iron fertilization. $\mathrm{Na}$ ture 407:695-702

15a. Brott LL, Nait RR, Pikas DJ, Kirkpatrick SM, Tomiln DW, et al. 2001. Ultrafast holographic nanopatterning of biocatalytically formed silica. Nature 413:2993
16. Brzezinski MA, Olson RJ, Chisholm SW. 1990. Silicon availability and cell-cycle progression in marine diatoms. Mar. Ecol. Prog. Ser. 67:83-96

17. Casotti R, Mazza S, Ianora A, Miralto A. 2001. Strategies to reduce mortality in marine and freshwater phytoplankton. ASLO Aquat. Sci. Meet. Spec. Sess., Albuquerque, New Mex.

18. Coale KH, Johnson KS, Fitzwater SE, Gordon RM, Tanner S, et al. 1996. A massive phytoplankton bloom induced by an ecosystem-scale iron fertilization experiment in the equatorial Pacific Ocean. $\mathrm{Na}$ ture 383:495-501

19. Curie C, Panaviene Z, Loulergue C, Dellaporta SL, Briat JF, et al. 2001. Maize yellow stripe1 encodes a membrane protein directly involved in $\mathrm{Fe}$ (III) uptake. Nature 409:346-49

20. Darley WM. 1968. Deoxyribonucleic acid content of the three cell types of Phaeodactylum tricornutum Bohlin. J. Phycol. 4:219-20

21. Delwiche CF, Palmer JD. 1997. The origin of plastids and their spread via secondary symbiosis. In Origins of Algae and Their Plastids, ed. D Bhattacharya, pp. 53-86. Vienna/New York: Springer Verlag

22. Douglas S, Zauner S, Fraunholz M, Beaton M, Penny S, et al. 2001. The highly reduced genome of an enslaved algal nucleus. Nature 410:1091-96

23. Dunahay TG, Jarvis EE, Dais SS, Roessler PG. 1996. Manipulation of microalgal lipid production using genetic engineering. Appl. Biochem. Biotech. 57/58:22331

24. Dunahay TG, Jarvis EE, Roessler PG. 1995. Genetic transformation of the diatoms Cyclotella cryptica and Navicula saprophila. J. Phycol. 31:1004-12

25. Escoubas J-M, Lomas M, LaRoche J, Falkowski PG. 1995. Light intensity regulation of $c a b$ gene transcription is signaled by the redox state of plastoquinone pool. Proc. Natl. Acad. Sci. USA 92:10237-41 
26. Falciatore A, Casotti R, Leblanc C, Abrescia C, Bowler C. 1999. Transformation of nonselectable reporter genes in marine diatoms. Mar. Biotech. 1:239-51

27. Falciatore A, Formiggini F, Bowler C. 2001. Reporter genes and in vivo imaging. In Molecular Plant Biology: A Practical Approach, ed. P Gilmartin, C Bowler, 2:265-83. Oxford, UK: Oxford Univ. Press

28. Falciatore A, Ribera D'Alcalà M, Croot P, Bowler C. 2000. Perception of environmental signals by a marine diatom. Science 288:2363-66

29. Falkowski PG, Barber RT, Smetacek V. 1998. Biogeochemical controls and feedbacks on ocean primary production. Science 281:200-6

30. Falkowski PG, LaRoche J. 1991. Acclimation to spectral irradiance in algae. $J$. Phycol. 27:8-14

31. Fischer H, Robl I, Sumper M, Kröger N. 1999. Targeting and covalent modification of cell wall and membrane proteins heterologously expressed in the diatom Cylindrotheca fusiformis (Bacillariophyceae). J. Phycol. 35:113-20

32. Fisher AE, Harrison PJ. 1996. Does carbohydrate content affect the sinking rate of marine diatoms? J. Phycol. 32:360-65

33. Furukawa T, Watanabe M, ShihiraIshikawa I. 1998. Green- and blue-lightmediated chloroplast migration in the centric diatom Pleurosira laevis. Protoplasma 203:214-20

34. Gibbs SP. 1981. The chloroplasts of some algal groups may have evolved from endosymbiotic eukaryotic algae. Ann. New York Acad. Sci. 361:193-208

35. Grossman AR. 2000. Chlamydomonas reinhardtii and photosynthesis: genetics to genomics. Curr. Opin. Plant Biol. 3: 132-37

36. Grossman AR, Schaefer MR, Chiang GG, Collier JL. 1993. Environmental effects on the light-harvesting complex of cyanobacteria. J. Bacteriol. 175:575-82

37. Guillou L, Chretiennot-Dinet MJ, Medlin
LK, Claustre H, Loiseaux-de Goer S, et al. 1999. Bolidomonas: a new genus with two species belonging to a new algal class, the Bolidophyceae (Heterokonta). J. Phycol. 35:368-81

38. Harper MA. 1977. Movements. In The Biology of Diatoms, ed. D Werner, pp. 224-49. Berkeley, CA: Univ. Calif. Press

38a. Harris EH. 2000. Chlamydomonas as a model organism. Annu. Rev. Plant Physiol. Plant Mol. Biol. 52:363-406

39. Hildebrand M, Dahlin K. 2000. Nitrate transporter genes from the diatom Cylindrotheca fusiformis (Bacillariophyceae): mRNA levels controlled by nitrogen source and by the cell cycle. J. Phycol. 36:702-13

40. Hildebrand M, Dahlin K, Volcani BE. 1998. Characterization of a silicon transporter gene family in Cylindrotheca fusiformis: sequences, expression analysis, and identification of homologs in other diatoms. Mol. Gen. Genet. 260:480-86

40a. Hildebrand M, Volcani BE, Gassmann W, Schroeder JI. 1997. A gene family of silicon transporters. Nature 385:68-89

41. Hutchins DA, Witter AE, Butler A, Luther GW III. 1999. Competition among marine phytoplankton for different chelated iron species. Nature 400:858-61

42. Jarvis EE, Dunahay TG, Brown LM. 1992. DNA nucleoside composition and methylation in several species of microalgae. J. Phycol. 28:356-62

43. Kagawa T, Sakai T, Suetsugu N, Oikawa K, Ishiguro S, et al. 2001. Arabidopsis NPL1: a phototropin homolog controlling the chloroplast high-light avoidance response. Science 291:2138-41

44. Kehoe DM, Grossman AR. 1996. Similarity of a chromatic adaptation sensor to phytochrome and ethylene receptors. Science 273:1409-12

45. Kemp AES, Pike J, Pearce RB, Lange CB. 2000. The "fall dump"-a new perspective on the role of a "shade flora" in the annual cycle of diatom production and export flux. Deep-Sea Res. 47:2129-54 
46. Kirk JTO. 1983. Light and Photosynthesis in Aquatic Ecosystems. Cambridge, UK: Cambridge Univ. Press

47. Kociolek JP, Stoermer EF. 1989. Chromosome numbers in diatoms: a review. Diatom Res. 4:47-54

48. Kowallik KV. 1992. Origin and Evolution of Plastids from Chlorophyll- $a+c$ Containing Algae: Suggested Ancestral Relationships to Red and Green Algal Plastids, ed. RA Lewin. New York/ London: Chapman Hall

49. Kröger N, Bergsdorf C, Sumper M. 1994. A new calcium-binding glycoprotein family constitutes a major diatom cell wall component. EMBO J. 13:4676-83

50. Kröger N, Bergsdorf C, Sumper M. 1996. Frustulins: domain conservation in a protein family associated with diatom cell walls. Eur. J. Biochem. 239:259-64

51. Kröger N, Deutzmann R, Bergsdorf C, Sumper M. 2000. Species-specific polyamines from diatoms control silica morphology. Proc. Natl. Acad. Sci. USA 97: 14133-38

52. Kröger N, Deutzmann R, Sumper M. 1999. Polycationic peptides from diatom biosilica that direct silica nanosphere formation. Science 286:1129-32

53. Kröger N, Lehmann G, Rachel R, Sumper M. 1997. Characterization of a 200$\mathrm{kDa}$ diatom protein that is specifically associated with a silica-based substructure of the cell wall. Eur. J. Biochem. 250:99105

54. Kröger N, Wetherbee R. 2000. Pleuralins are involved in theca differentiation in the diatom Cylindrotheca fusiformis. Protist 151:263-73

55. Lang M, Apt KE, Kroth PG. 1998. Protein transport into "complex" diatom plastids utilizes two different targeting signals. J. Biol. Chem. 273:30973-78

56. LaRoche J, Boyd PW, McKay RML, Geider RJ. 1996. Flavodoxin as an in situ marker for iron stress in phytoplankton. Nature 382:802-5

57. LaRoche J, Mortain-Bertrand A, Falkow- ski PG. 1991. Light intensity-induced changes in $c a b$ mRNA and light-harvesting complex II apoprotein levels in the unicellular chlorophyte Dunaliella tertiolecta. Plant Physiol. 97:147-53

58. Leblanc C, Falciatore A, Bowler C. 1999. Semi-quantitative RT-PCR analysis of photoregulated gene expression in marine diatoms. Plant Mol. Biol. 40:1031-44

59. Lee RE. 1999. Heterokontophyta, Bacillariophyceae. In Phycology, ed. RE Lee, pp. 415-58. Cambridge, UK: Cambridge Univ. Press

60. Lewin JC. 1958. The taxonomic position of Phaeodactylum tricornutum. J. Gen. Microbiol. 18:427-32

61. Lewin JC, Lewin RA, Philpott DE. 1958. Observations on Phaeodactylum tricornutum. J. Gen. Microbiol. 18:418-26

62. Mann DG. 1993. Patterns of sexual reproduction in diatoms. Hydrobiologia 269/270:11-20

63. Mann S, Ozin GA. 1996. Synthesis of inorganic materials with complex form. Nature 382:313-18

64. Martin JH, Coale KH, Johnson KS, Fitzwater SE, Gordon RM, et al. 1994. Testing the iron hypothesis in ecosystems of the equatorial Pacific Ocean. Nature 371:123-29

65. Martin-Jezequel V, Hildebrand M, Brzezinski MA. 2000. Silicon metabolism in diatoms: implications for growth. J. Phycol. 36:821-40

66. Medlin LK, Kooistra WCH, Schmid A-MM. 2000. A review of the evolution of the diatoms - a total approach using molecules, morphology and geology. In The Origin and Early Evolution of the Diatoms: Fossil, Molecular and Biogeographical Approaches, ed. A Witkowski, J Sieminska, pp. 13-35. Cracow: W Szafer Inst. Bot., Pol. Acad. Sci.

67. Medlin LK, Kooistra WHCF, Gersonde R, Sims PA, Wellbrock U. 1997. Is the origin of the diatoms related to the endPermian mass extinction? Nova Hedwigia 65:1-11 
68. Mewes HW, Albermann K, Bahr M, Frishman D, Gleissner A, et al. 1997. Overview of the yeast genome. Nature 387 (Suppl.):7-65

69. Miralto A, Barone G, Romano G, Poulet SA, Ianora A, et al. 1999. The insidious effect of diatoms on copepod reproduction. Nature 402:173-76

70. Morse DE. 1999. Silicon biotechnology: harnessing biological silica production to construct new materials. Trends Biotechnol. 17:230-32

71. Norton TA, Melkonian M, Andersen RA. 1996. Algal biodiversity. Phycologia 35: 308-26

72. Owens TG. 1986. Light-harvesting function in the diatom Phaeodactylum tricornutum. Plant Physiol. 80:732-38

73. Parkinson J, Gordon R. 1999. Beyond micromachining: the potential of diatoms. Trends Biotechnol. 17:190-96

74. Parsek M, Greenberg EP. 2000. Acylhomoserine lactone quorum sensing in Gram-negative bacteria: a signaling mechanism involved in associations with higher organisms. Proc. Natl. Acad. Sci. USA 97:8789-93

75. Pickett-Heaps J, Schmid A-MM, Edgar LA. 1990. The cell biology of diatom valve formation. In Progress in Phycological Research, ed. FE Round, DJ Chapman. 7:1-168. Bristol, UK: BioPress Ltd.

76. Qiu Y-L, Palmer JD. 1999. Phylogeny of early land plants: insights from genes and genomes. Trends Plant Sci. 4:26-30

77. Reinfelder JR, Kraepiel AML, Morel FMM. 2000. Unicellular $C_{4}$ photosynthesis in a marine diatom. Nature 407:99699

78. Scala S, Bowler C. 2001. Molecular insights into the novel aspects of diatom biology. Cell. Mol. Life Sci. 58:1666-73

79. Scala S, Carels N, Falciatore A, Chiusano ML, Bowler C. 2002. Genome properties of the diatom Phaeodactylum tricornutum and comparison with the genomes of other eukaryotes. Plant Physiol. In press
80. Sineshchekov OA, Govorunova EV. 1999. Rhodopsin-mediated photosensing in green flagellated algae. Trends Plant Sci. 4:58-63

81. Smetacek V. 1999. Diatoms and the ocean carbon cycle. Protist 150:25-32

82. Smetacek V. 2001. A watery arms race. Nature 411:745

83. Smith NA, Singh SP, Wang MB, Stoutjesdijk PA, Green AG, et al. 2000. Total silencing by intron-spliced hairpin RNAs. Nature 407:319-20

84. Tréguer P, Nelson DM, Van Bennekom AJ, DeMaster DJ, Leynaert A, et al. 1995. The silica balance in the world ocean: a reestimate. Science 268:375-79

85. Trewavas A. 2000. Signal perception and transduction. In Biochemistry and Molecular Biology of Plants, ed. BB Buchanan, W Gruissem, RL Jones, pp. 930-87. Rockville, MA: Am. Soc. Plant Physiol.

86. Valentin K, Cattolico RA, Zetsche K. 1992. Phylogenetic Origin of the Plastids. New York/London: Chapman Hall

87. van de Poll WH, Vrieling EG, Gieskes WWC. 1999. Location and expression of frustulins in the pennate diatoms Cylindrotheca fusiformis, Navicula pelliculosa, and Navicula salinarum (Bacillariophyceae). J. Phycol. 35:1044-53

88. Van Den Hoek C, Mann DG, Johns HM. 1997. Algae. An Introduction to Phycology. Cambridge, UK: Cambridge Univ. Press

89. Vaulot D, Olson RJ, Chisholm SW. 1986. Light and dark control of the cell cycle in two phytoplankton species. Exp. Cell Res. 167:38-52

89a. Vaulot D, Olson RJ, Merkel SM, Chisholm SW. 1987. Cell cycle response to nutrient starvation in two marine phytoplankton species. Mar. Biol. 95:625-30

90. Veldhuis MJW, Cucci TL, Sieracki ME. 1997. Cellular DNA content of marine phytoplankton using two new fluorochromes: taxonomic and ecological implications. J. Phycol. 33:527-41

91. Villareal TA. 1989. Division cycles in 
the nitrogen-fixing Rhizosolenia (Bacillariophyceae)-Richelia (Nostocaceae) symbiosis. Br. Phycol. J. 24:357-65

92. Wolfe GR, Cunningham FX, Durnford D, Green BR, Gantt E. 1994. Evidence for a common origin of chloroplasts with light-harvesting complexes of different pigmentation. Nature 367:566-68

93. Zamore PD, Tuschl T, Sharp PA, Bartel DP. 2000. RNAi: double-stranded RNA directs the ATP-dependent cleavage of mRNA at 21 to 23 nucleotide intervals. Cell 101:25-33

94. Zaslavskaia LA, Lippmeier JC, Kroth
PG, Grossman AR, Apt KE. 2000. Transformation of the diatom Phaeodactylum tricornutum (Bacillariophyceae) with a variety of selectable marker and reporter genes. J. Phycol. 36:379-86

95. Zaslavskaia LA, Lippmeier JC, Shih C, Ehrhardt D, Grossman AR, et al. 2001. Trophic conversion of an obligate photoautotrophic organism through metabolic engineering. Science 292:2073-75

96. Zurzolo C, Bowler C. 2001. Exploring bioinorganic pattern formation in diatoms. A story of polarized trafficking. Plant Physiol. 127:1339-45 


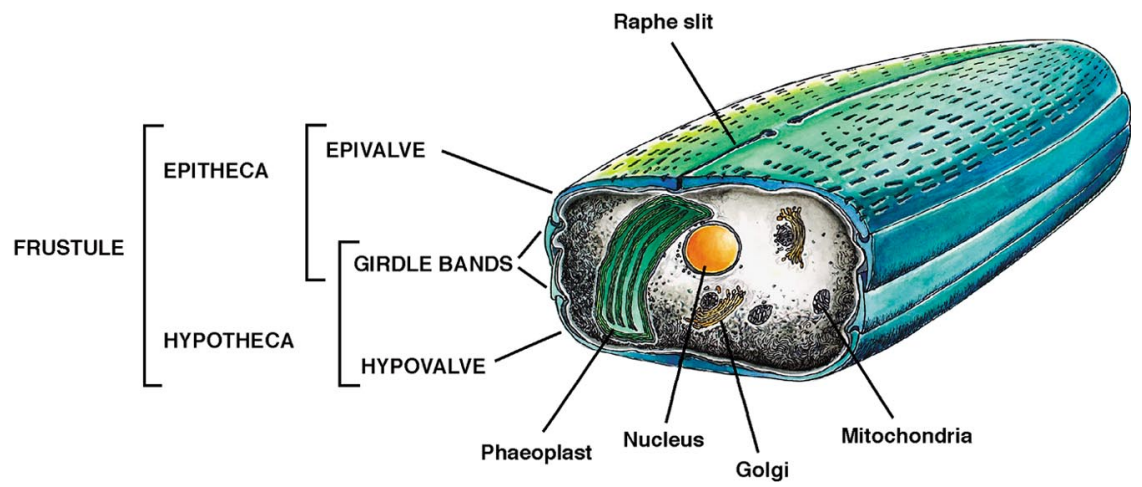

Figure 2 Schematic overview of the general structural features of a pennate diatom. See text for further details. 


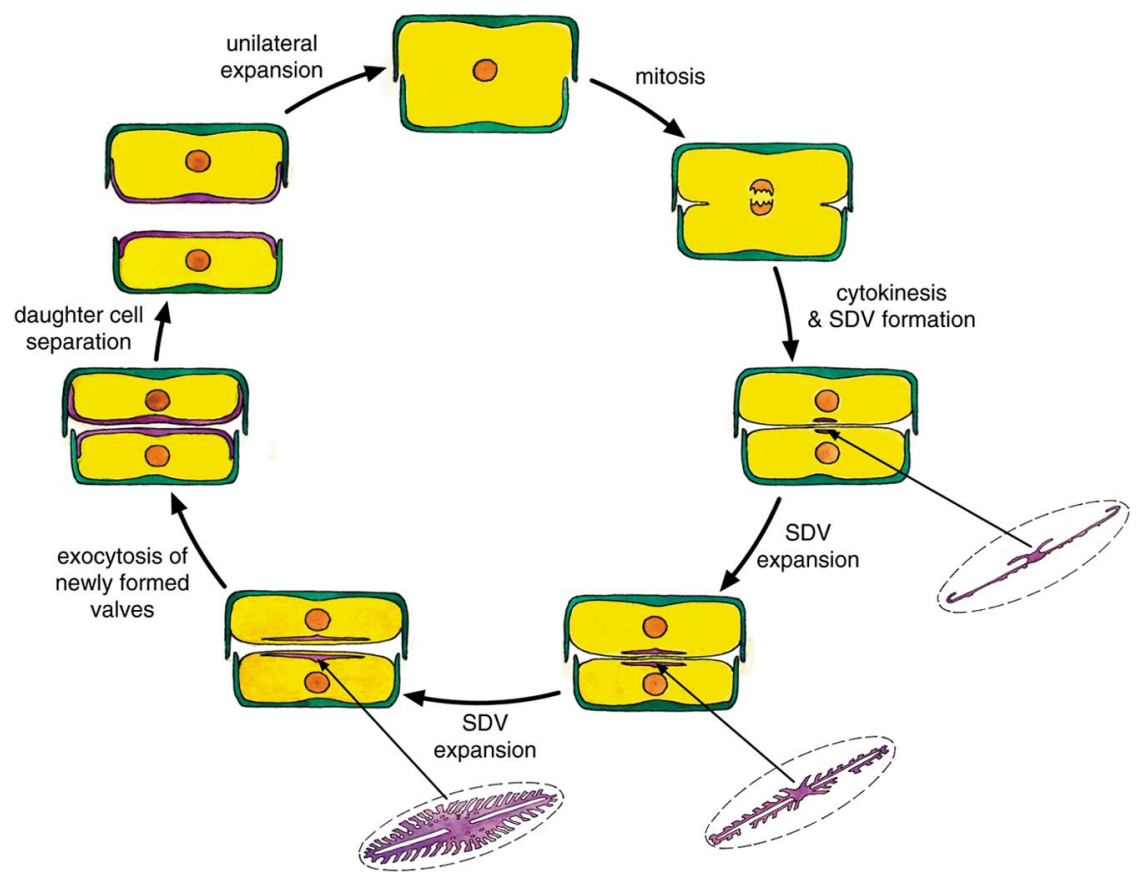

Figure 3 Schematic overview of mitotic cell division and hypovalve formation in a pennate diatom. Following mitosis and cytokinesis, a specialized vesicle known as the silica deposition vesicle (SDV) forms between the nucleus and the plasma membrane, at a position where the new hypovalve will be generated. The SDV elongates into a tube and then spreads out perpendicularly to eventually form a huge vesicle along one side of the cell. A new valve is formed within the SDV by the transport of silica, proteins, and polysaccharides into it, and once complete, it is exocytosed from the cell. The two daughter cells can then separate and grow unidirectionally along the cell division axis by the biogenesis of girdle bands, which are also formed within SDVs. However, one daughter cell is always smaller than the other, owing to the different sizes of the parental thecae from which they are derived. For more details see text and Reference (96). Cell division in centric diatoms is similar, although the timing of events can be different (75). 


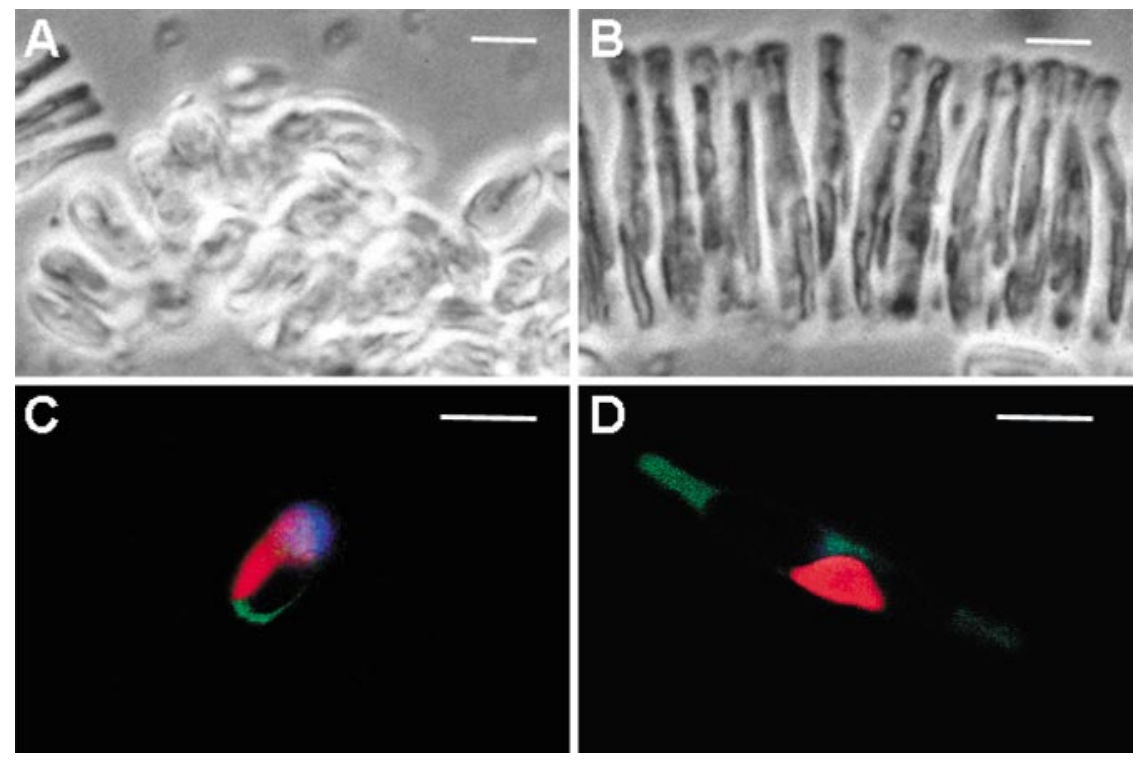

Figure 4 The diatom $P$. tricornutum. Oval $(A, C)$ and fusiform $(B, D)$ morphotypes. The top panels show transmitted light images of cells. Oval cells produce a large amount of mucilage and tend to form aggregates $(A)$. Fusiform cells grown on agar plates can form chains $(B)$. The lower panels show fluorescence of oval $(C)$ and fusiform $(D)$ cells genetically transformed with a cytosolic GFP construct. Green, GFP; red, chlorophyll fluorescence; blue, nuclei. Scale bars are $5 \mu \mathrm{m}$. Images courtesy of O. Malakhova \& M. Mutarelli. 